\title{
Human intestinal macrophages display profound inflammatory anergy despite avid phagocytic and bacteriocidal activity
}

\author{
Lesley E. Smythies, ${ }^{1}$ Marty Sellers, ${ }^{2}$ Ronald H. Clements, ${ }^{2}$ Meg Mosteller-Barnum, ${ }^{1}$ \\ Gang Meng, ${ }^{1}$ William H. Benjamin, ${ }^{3}$ Jan M. Orenstein, ${ }^{4}$ and Phillip D. Smith ${ }^{1,5}$ \\ ${ }^{1}$ Department of Medicine (Gastroenterology), ${ }^{2}$ Department of Surgery (Transplantation and Gastrointestinal), and \\ ${ }^{3}$ Department of Pathology, University of Alabama at Birmingham, Birmingham, Alabama, USA. ${ }^{4}$ Department of Pathology, \\ George Washington University, Washington, D.C., USA. ${ }^{5}$ Veterans Affairs Medical Center, Birmingham, Alabama, USA.
}

\begin{abstract}
Intestinal macrophages, which are thought to orchestrate mucosal inflammatory responses, have received little investigative attention compared with macrophages from other tissues. Here we show that human intestinal macrophages do not express innate response receptors, including the receptors for LPS (CD14), Fc $\alpha$ (CD89), Fc $\gamma$ (CD64, CD32, CD16), CR3 (CD11b/CD18), and CR4 (CD11c/CD18); the growth factor receptors IL-2 (CD25) and IL-3 (CD123); and the integrin LFA-1 (CD11a/CD18). Moreover, resident intestinal macrophages also do not produce proinflammatory cytokines, including IL-1, IL-6, IL-10, IL-12, RANTES, TGF- $\beta$, and TNF- $\alpha$, in response to an array of inflammatory stimuli but retain avid phagocytic and bacteriocidal activity. Thus, intestinal macrophages are markedly distinct in phenotype and function from blood monocytes, although intestinal macrophages are derived from blood monocytes. To explain this paradox, we show that intestinal stromal cell-derived products downregulate both monocyte receptor expression and, via TGF- $\beta$, cytokine production but not phagocytic or bacteriocidal activity, eliciting the phenotype and functional profile of intestinal macrophages. These findings indicate a mechanism in which blood monocytes recruited to the intestinal mucosa retain avid scavenger and host defense functions but acquire profound "inflammatory anergy," thereby promoting the absence of inflammation characteristic of normal intestinal mucosa despite the close proximity of immunostimulatory bacteria.
\end{abstract}

\section{Introduction}

The gastrointestinal mucosa contains the largest reservoir of macrophages in the body (1) and is the largest body surface to interface with the external environment (2). In this unique compartment, intestinal macrophages are the first phagocytic cells of the innate immune system to interact with microorganisms and microbial products that have breached the epithelium. Located in the subepithelial lamina propria, intestinal macrophages have the dual role of protecting the host against foreign pathogens and regulating mucosal responses to commensal bacteria.

Interactions between phagocytes and Gram-negative bacteria or their products involve CD14, a glycosylphosphatidyl inositol-linked glycoprotein present on mononuclear and polymorphonuclear phagocytes. CD14 acts as a high-affinity receptor for complexes of LPS and LPS-binding protein (3). The binding of LPS to CD14 and then to toll receptor-4 results in the production of key proinflammatory cytokines, including IL-1, IL-6, IL-8, and TNF- $\alpha$, which mediate inflammatory reactions. Surprisingly, intestinal macrophages lack CD14 $(4,5)$, and colonic macrophages express low levels of CD14 $(6,7)$. The downregulated expression of CD14 on intestinal macrophages

Nonstandard abbreviations used: ASFV, African swine fever virus; CM, conditioned media; E-CM, epithelial cell-CM; HK, heat-killed; MNL-CM, mononuclear cell-CM; S-CM, stromal cell-CM; TSLP, thymic stromal lymphopoietin.

Conflict of interest: The authors have declared that no conflict of interest exists.

Citation for this article: J. Clin. Invest. 115:66-75 (2005).

doi:10.1172/JCI200519229. likely serves to dampen the LPS-induced response of intestinal macrophages to lumenal bacteria and their LPS.

Here we extend our previous finding that intestinal macrophages are downregulated for LPS- and IgA-mediated IL-8 production (5) to show that resident intestinal macrophages are downregulated for the expression of an array of innate response and growth factor receptors and for the production of all major proinflammatory cytokines, but retain avid phagocytic and bacteriocidal activity for Salmonella typhimurium and Escherichia coli. We also show that factors released by lamina propria stromal (mesenchymal) cells downregulate monocyte expression of proinflammatory receptors and, through the release of TGF- $\beta$, production of proinflammatory cytokines, but do not alter intestinal macrophage phagocytic or bacteriocidal activity. These findings indicate a mechanism whereby proinflammatory blood monocytes recruited to the mucosa retain scavenger and host defense function, but acquire profound "inflammatory anergy," thus promoting the absence of inflammation characteristic of normal intestinal mucosa despite the close proximity of huge numbers of immunostimulatory bacteria.

\section{Results}

Intestinal macrophages display a distinct phenotype. The lamina propria macrophages and blood monocytes used in the following experiments displayed ultrastructural features characteristic of macrophages and monocytes, respectively (Figure 1). Both cell populations expressed equivalent levels of HLA-DR and CD13 (aminopeptidase $\mathrm{N}$, which is present on mononuclear phagocytes but not T, B, or NK cells), but no CD3, CD20, CD69, or CD83, 
Intestinal macrophages

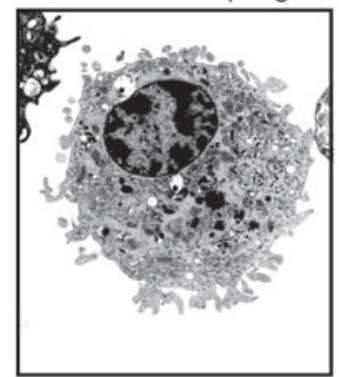

Blood monocytes

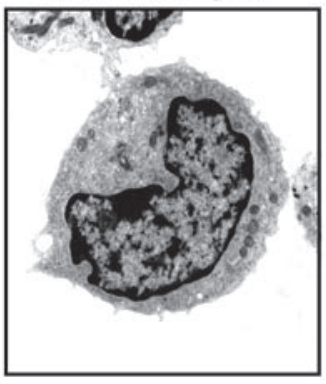

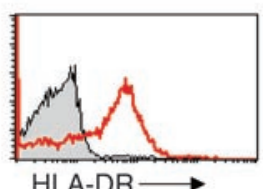

HLA-DR $\longrightarrow$
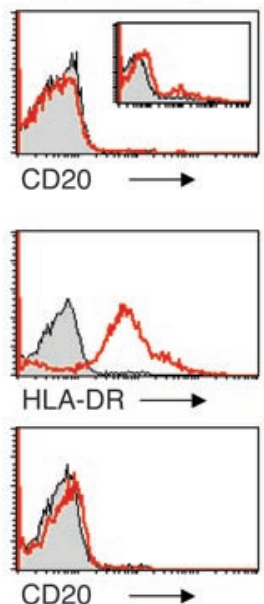

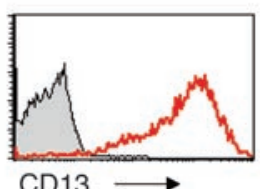

$\mathrm{CD} 13 \longrightarrow$

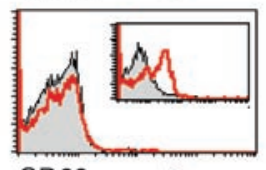

CD69 $\longrightarrow$
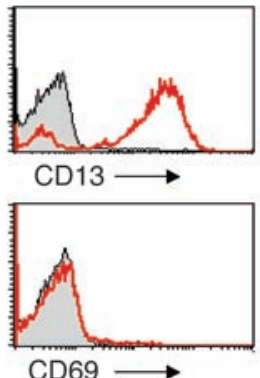
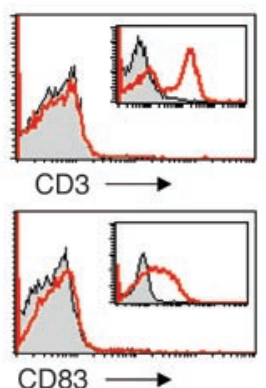

$\mathrm{CD} 83 \longrightarrow$
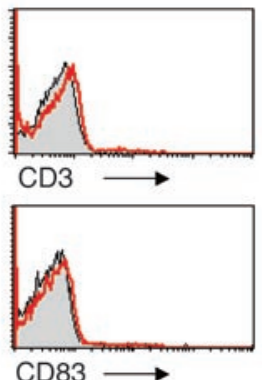

\section{Figure 1}

Ultrastructure and purity of intestinal macrophages and blood monocytes. A representative intestinal macrophage and blood monocyte show typical eccentric nuclei, villous processes (especially on the intestinal macrophage), and in the macrophage, primary and secondary lysosomes and phagocytic vacuoles (magnification, $\times 10,000)$. FACS profiles for intestinal macrophages and blood monocytes show that both populations express the mononuclear phagocyte markers HLA$\mathrm{DR}$ and CD13, but not markers for T cells (CD3), B cells (CD20), NK cells (CD69), or DCs (CD83). Insets show control cells stained with CD3 (PBLs), CD20 (PBLs), CD69 (PBLs), and CD83 (monocytederived DCs). Both populations also did not express CD33, CD34, or CD103, markers for bone marrow macrophage precursors, follicular DCs and intestinal lymphocytes, respectively. indicating no detectable T, B, NK cells, or DCs, respectively (Figure 1). Intestinal macrophages did not express CD14 or CD89, a previously reported characteristic of intestinal macrophages (5), nor did they express FcyRI-III (CD64, CD32, CD16) or CD11a, CD11b, CD11c, or CD18, whereas each receptor was strongly expressed on monocytes from the same donor (Table 1). The absence of the LPS receptor CD14 on intestinal macrophages is not restricted to human cells, since murine $\mathrm{F} 4 / 80^{+}$intestinal macrophages also lack this receptor (data not shown). Intestinal macrophages also did not express inducible CD25 or CD123, receptors for the growth factor cytokines IL-2 and IL-3, respectively, which were expressed on monocytes. In addition, intestinal macrophages cultured for 45 days in RPMI expressed HLA-DR and CD13, but not the above receptors or integrin, indicating that prolonged culture in the absence of mucosal factors did not induce expression (or re-expression) of the receptors. Scavenger receptor CD36 was present on macrophages, however, albeit at markedly reduced levels compared with monocytes. Thus, intestinal macrophages do not express receptors for LPS, IgA, IgG, C3 (CD11b/CD18), C4 (CD11c/CD18), IL-2 and IL-3, or the integrin LFA-1 (CD11a/CD18), which are constitutively expressed or inducible on blood monocytes.

Intestinal macrophages are downregulated for the production of proinflammatory cytokines. Although macrophages from other tissues such as the lung have been shown to release lower levels of some cytokines than blood monocytes (8), little is known about the regulation of cytokine production by intestinal macrophages. Therefore, purified intestinal macrophages and blood monocytes were evaluated for LPS-stimulated cytokine production. Surprisingly, lamina propria macrophages stimulated with LPS for 24 hours released no detectable IL-1, IL-6, or TNF- $\alpha$, and, compared with monocytes, at least four logs less IL-8 (Figure 2). LPS-stimulated macrophages also contained no intracellular IL-1, IL-6, TNF- $\alpha$, or IL- 8 as analyzed by flow cytometry (data not shown). In contrast, blood monocytes, which had been treated similarly and were from the same donors, produced nanogram levels of each cytokine after stimulation (Figure 2). Neither culture of macrophages for up to 45 days prior to stimulation, nor increase of the incubation time after stimulation to 72 hours, changed this cytokine profile.

One explanation for the profound downregulation of LPSstimulated cytokine production by intestinal macrophages is the absence of surface CD14 (5), the primary receptor for LPS. Intestinal macrophages incubated for 24 hours with an array of stimuli, however, including $H$. pylori urease, heat-killed (HK) Staphylococcus aureus, IFN- $\gamma$, and PMA, released no detectable IL-1, IL-6, or TNF- $\alpha$, and again barely detectable levels of IL-8, whereas similarly treated monocytes released large amounts

\section{Table 1}

Expression of surface antigens and receptors on matched intestinal macrophages and blood monocytes ${ }^{A}$

\begin{tabular}{|c|c|c|}
\hline & $\begin{array}{c}\text { Intestinal } \\
\text { macrophages }\end{array}$ & $\begin{array}{c}\text { Blood } \\
\text { monocytes }\end{array}$ \\
\hline HLA-DR & 85.1 & 87.9 \\
\hline CD13 (aminopeptidase N) & 90.8 & 94.7 \\
\hline CD14 (LPS-R) & 0.2 & 93.6 \\
\hline CD89 (FcaR) & 0.5 & 91.4 \\
\hline CD16 (FcyRIII) & 1.4 & 19.8 \\
\hline CD32 (FC $\gamma \mathrm{RII})$ & 0.1 & 78.6 \\
\hline CD64 (FcүRI) & 0.7 & 49.1 \\
\hline CD11a (integrin $\alpha$, LFA-1) & 0.2 & 95.0 \\
\hline CD11b (integrin $\alpha, M A C-1$ ) & 0.6 & 75.2 \\
\hline CD11c (integrin $\alpha$ ) & 0.2 & 86.6 \\
\hline CD18 (integrin $\beta 2$ ) & 0.2 & 93.6 \\
\hline CD25 (IL-2R) & 0.3 & 3.7 \\
\hline $\mathrm{CD} 25+\mathrm{LPS}^{\mathrm{B}}$ & 0.2 & 24.7 \\
\hline CD123 (IL-3R $\alpha)$ & 0.1 & 19.2 \\
\hline CD36 (scavenger receptor B) & 9.9 & 73.8 \\
\hline
\end{tabular}

APercentage of cells from a representative experiment $(n=8) .{ }^{\mathrm{B} C e l l s}$ incubated with LPS $(1 \mu \mathrm{g} / \mathrm{ml})$ for 24 hours. 


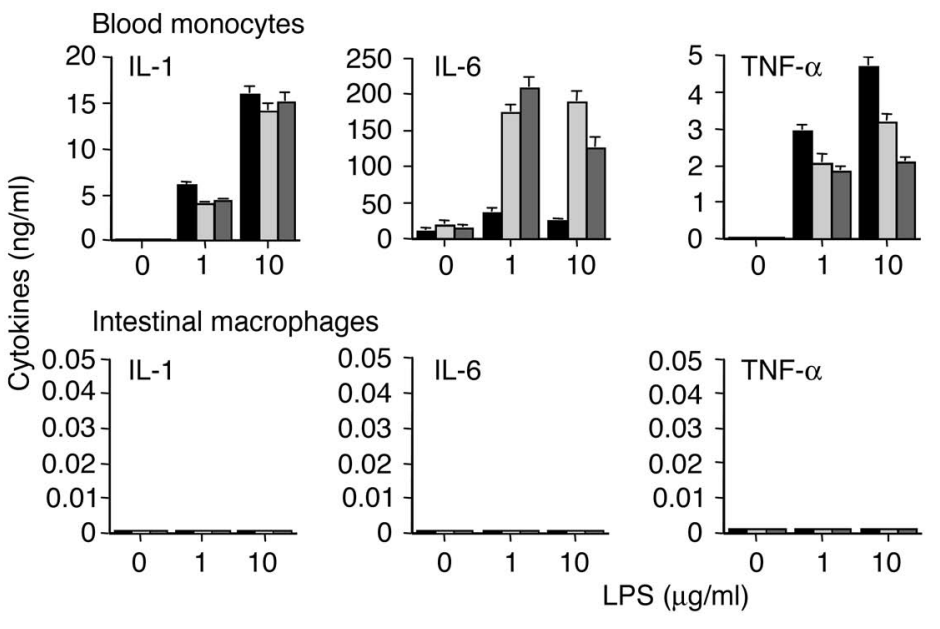

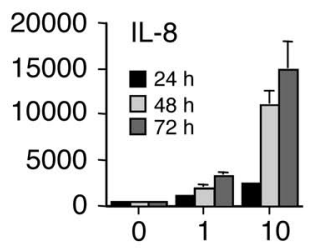

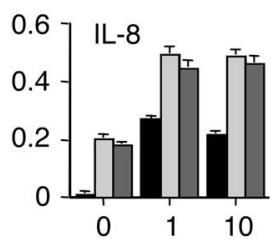

Figure 2

Downregulated cytokine production by LPS-stimulated intestinal macrophages. Blood monocytes and intestinal macrophages $\left(2 \times 10^{6} / \mathrm{ml}\right)$ were incubated with or without LPS for 24,48 , and 72 hours, and supernatants were assayed for IL-1, IL-6, TNF- $\alpha$, and IL-8. Values are mean + $\mathrm{SD}(n=3)$. of the cytokines (Figure 3$)$. In additional experiments $(n=6)$, intestinal macrophages also did not release IL-12 or the antiinflammatory cytokines IL-10 or TGF- $\beta$ in response to the same stimuli. Prolonged culture (up to 45 days) of the macrophages followed by incubation with the same stimuli or optimal concentrations of muramyl dipeptide, TNF- $\alpha$, or IFN- $\gamma$ plus LPS did not induce cytokine release. Taken together, these findings indicate a global, stimulus-independent inability of intestinal macrophages to produce proinflammatory cytokines.

Stromal cell-conditioned media induces an intestinal macrophage phenotype in blood monocytes. Since intestinal macrophages and blood monocytes differ functionally and phenotypically, yet macrophages are derived from blood monocytes $(6,9)$, we next determined whether factors produced by intestinal stromal, epithelial, or mononuclear cells could downregulate monocyte innate response receptors and surface antigens. Consistent with our earlier findings (5), phenotypic changes were not detectable in the monocytes within the first 24 hours of exposure to stromal cell-conditioned media (S-CM). Prolonged exposure of monocytes to S-CM, but not epithelial cell-CM (E-CM) or mononuclear cell-CM (MNL-CM), however, caused a dose- and time-dependent reduction in the expression of CD14 and CD16 innate response receptors (Figure 4). The decrease in receptor expression became detectable after the monocytes had been incubated with S-CM for 36-48 hours; by 72-96 hours of incubation, pronounced loss of receptors was detected in monocytes incubated with S-CM, but not in monocytes incubated in media alone,
E-CM, or MNL-CM. Phenotypic changes induced by S-CM persisted for at least 7 days. S-CM also caused a marked downregulation of monocyte $\mathrm{C}$-C chemokine receptor 5 (CCR5; G. Meng, unpublished data) and the chemotactic ligand receptors for $\mathrm{C} 5 \mathrm{a}$ and f-met-leu-phe (M. Sellers, unpublished data); neither receptor is expressed on intestinal macrophages. In contrast, levels of the monocyte/macrophage surface antigens HLA-DR and CD13 were not altered by exposure to S-CM. Preincubation of S-CM with a cocktail of protease inhibitors did not affect the ability of S-CM to downregulate receptors (Figure 4B), indicating that the downregulation was not the result of residual protease carried over from the isolation. Importantly, S-CM did not contain immunoassay-detectable levels of other regulatory cytokines, including GM-CSF, M-CSF, IL-3, IL-4, and IL-10.

$S$-CM downregulates monocyte release of proinflammatory cytokines. Having shown that S-CM induces blood monocytes to differentiate into an intestinal macrophage phenotype, we next determined the effect of S-CM on the production of proinflammatory cytokines by monocytes. Monocytes were preincubated with S-CM for 1 hour and then incubated with $H$. pylori urease, an LPS-independent stimulus of monocyte cytokine production $(10,11)$, for 24 hours. S-CM caused a marked, dose-dependent decline in the release of inducible IL-1, IL-6, TNF- $\alpha$, IL-10, and RANTES (Figure 5). S-CM also caused dose-dependent reductions in the release of these cytokines by LPS- and IFN- $\gamma$-stimulated monocytes, as well as splenic macrophages (data not shown). In sharp contrast to the downregulatory effect of S-CM,

\section{Figure 3}

Stimulus-independent downregulation of intestinal macrophage cytokine production. Blood monocytes and intestinal macrophages $\left(2 \times 10^{6} / \mathrm{ml}\right)$ were incubated with and without $H$. pylori urease $(10 \mu \mathrm{g} / \mathrm{ml})$, HK $S$. aureus $\left(10^{7} \mathrm{CFU} / \mathrm{ml}\right), \mathrm{IFN}-\gamma(100 \mathrm{U} / \mathrm{ml})$, and PMA (40 ng/ml) for 24 hours, and supernatants were assayed for IL-1, IL-6, TNF- $\alpha$, and IL-8. Values are mean $+\mathrm{SD}(n=3)$.

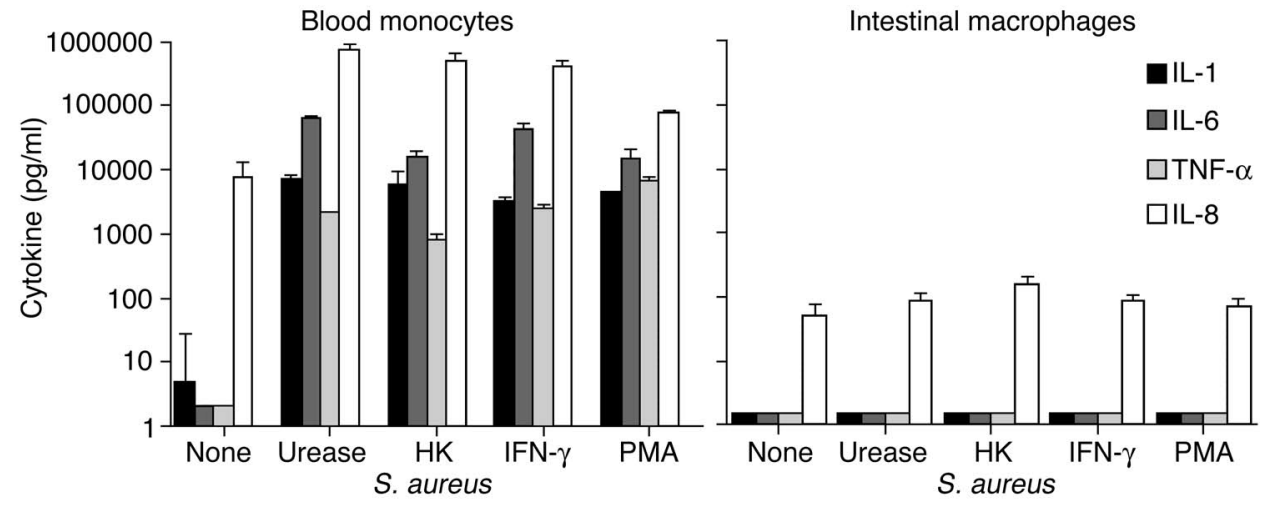




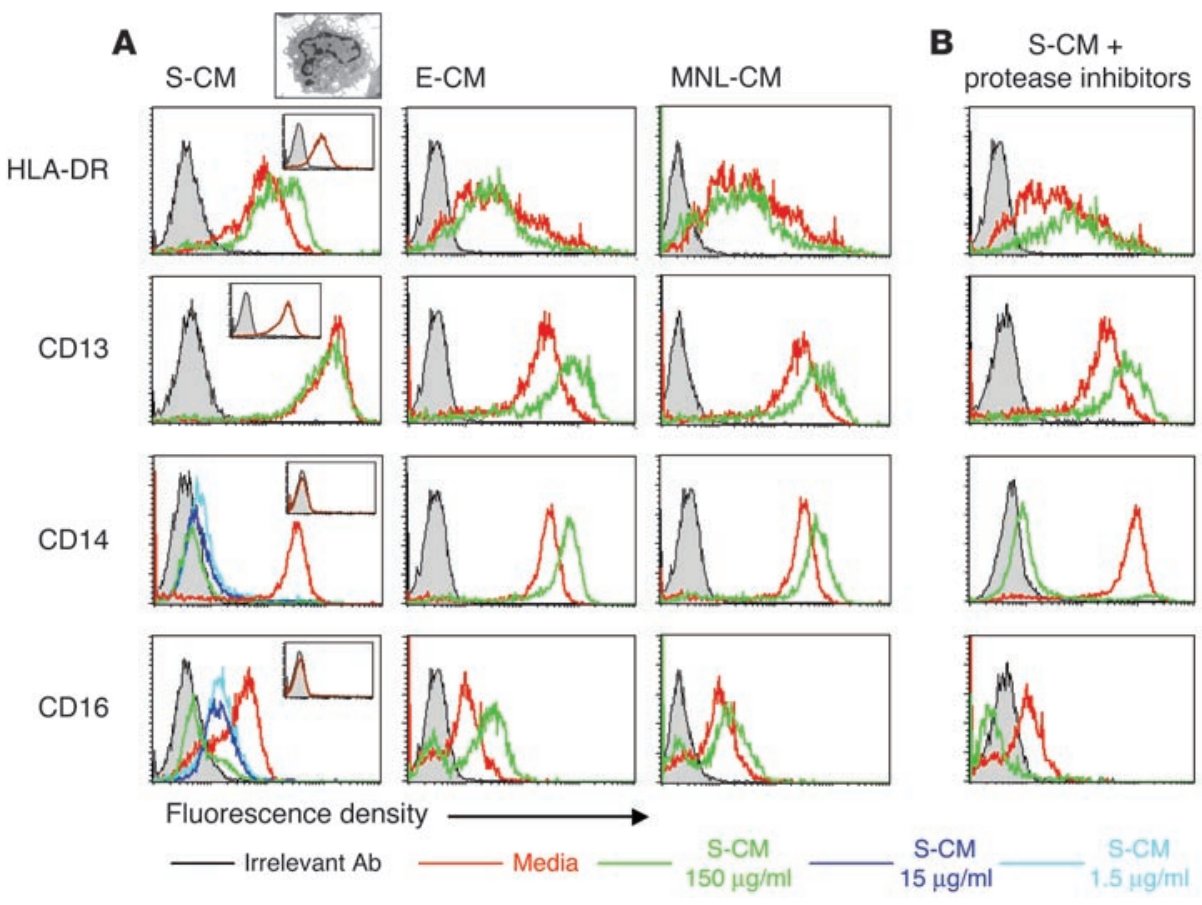

\section{Figure 4}

S-CM downregulation of monocyte surface antigen expression. (A) Blood monocytes cultured for 4 days in the absence or presence of S-CM, E-CM, or MNL-CM at the indicated concentrations were analyzed by FACS for HLA-DR, CD13, CD14, and CD16 (open histograms). Cells were also stained with FITC IgG1 and PE IgG2a irrelevant Abs (solid histograms). FACS insets show the flow-cytometric analysis of intestinal macrophages for the same surface marker. Data are from a representative experiment $(n=3)$. Electron micrograph inset shows a representative monocyte after 24-hour culture with S-CM $(150 \mu \mathrm{g} / \mathrm{ml}$ total protein). (B) Blood monocytes incubated with S-CM $(150 \mu \mathrm{g} / \mathrm{ml}$ total protein) and in the absence or presence of protease inhibitors, including trypsin, chymotrypsin, pronase, thermolysin, papain, and pancreas extract, as described in Methods, were analyzed by FACS as above.
E-CM and MNL-CM did not affect monocyte cytokine release (Figure 5). Monocyte viability as measured by FACS analysis of propidium iodide uptake was not affected by S-CM. Thus, S-CM caused a dose-dependent, stimulus-independent decline in monocyte cytokine release, resulting in a cytokine profile characteristic of intestinal macrophages.

Intestinal macrophages are strongly phagocytic, but phagocytosis does not stimulate cytokine release. Extending our previous results (5), both monocytes and intestinal macrophages showed avid phagocytic activity for FITC-labeled microspheres (Figure 6A). Phagocytosis induced blood monocytes, however, but not intestinal macrophages, to release abundant levels of IL-1, IL-6, TNF- $\alpha$, and IL-8 (Figure 6B). Thus, similar to blood monocytes and other tissue macrophages, intestinal macrophages are avidly phagocytic; but, in sharp contrast to blood monocytes and macrophages from other sites (12), intestinal macrophages do not release proinflammatory cytokines after phagocytosis.

S-CM downregulates phagocytosis-driven cytokine release, but not phagocytosis, by monocytes. Having shown that S-CM downregulates cytokine production by $H$. pylori urease-stimulated monocytes (Figure 5), we determined whether S-CM downregulates monocyte phagocytosis and phagocytosis-induced cytokine release. S-CM did not reduce monocyte phagocytosis of FITC-labeled microspheres (Figure 6A). Rather, S-CM caused a modest increase in monocyte phagocytosis, suggesting that stromal cell products may contribute to the increased phagocytic activity of intestinal macrophages relative to that of blood monocytes, which we have observed previously (5). In parallel cultures, however, S-CM caused a dose-dependent decline in phagocytosis-driven cytokine release by monocytes, as shown for IL-1 and TNF- $\alpha$ (Figure 6B, inset). Thus, S-CM enhanced the phagocytic capability of blood monocytes while decreasing their release of cytokines in response to phagocytosis.

Intestinal macrophages are bacteriocidal for S. typhimurium and E. coli. In agreement with the ability of intestinal macrophages to phagocytose Candida albicans (4), intestinal macrophages and blood monocytes avidly phagocytosed both S. typhimurium and E. coli (Figure 6, C and D), killing more than $99 \%$ of phagocytosed bacteria within the first 30 to 60 minutes of incubation. The number of surviving intracellular S. typhimurium decreased to a nadir at 150 minutes and increased slightly thereafter, consistent with replication of the few bacteria remaining in the macrophages (13). Monocytes phagocytosed as many bacteria as the macrophages, but the numbers of live bacteria recovered from lysed macrophages were one log less than those recovered from blood monocytes, suggesting that intestinal macrophages were more bacteriocidal for S. typhimurium and E. coli than monocytes. Importantly, preincubation of monocytes with S-CM did not affect the ability of monocytes to phagocytose or kill the bacteria.

Role for TGF- $\beta$ in S-CM-mediated inbibition of monocyte cytokine release. We next investigated the mechanism by which S-CM downregulates monocyte cytokine release. The preincubation of monocytes with S-CM caused a dose-dependent decrease in LPSinduced TNF- $\alpha$ protein and mRNA expression and a reciprocal increase in TGF- $\beta$ release, a key regulatory cytokine with potent inhibitory effects on monocyte function (14-16) (Figure 7A). S-CM inhibition of phagocytosis-induced IL- 1 and TNF- $\alpha$ release (Figure $6 \mathrm{~B}$, inset) also was associated with the dose-dependent release of TGF- $\beta$ (data not shown). S-CM did not contain or induce detectable levels of IL-10 or IL-4, other cytokines known to downregulate monocytes, and preincubation of S-CM with either anti-IL-10 or anti-IL-4 Abs did not affect the downregulatory activity of S-CM. Thus, exposure of monocytes to S-CM inhibited monocyte cytokine production while simultaneously stimulating monocyte release of TGF- $\beta$. The amount of TGF- $\beta(390 \mathrm{pg} / \mathrm{ml})$ detected in the LPS-stimulated monocyte cultures at the highest concentration of S-CM $(150 \mu \mathrm{g} / \mathrm{ml}$ total protein $)$ exceeded the amount of TGF- $\beta$ detected in S-CM alone $(16 \mathrm{pg} / \mathrm{ml})$. These data suggest that factors in the S-CM, possibly the TGF- $\beta$ itself, induced monocyte production of TGF- $\beta$. 


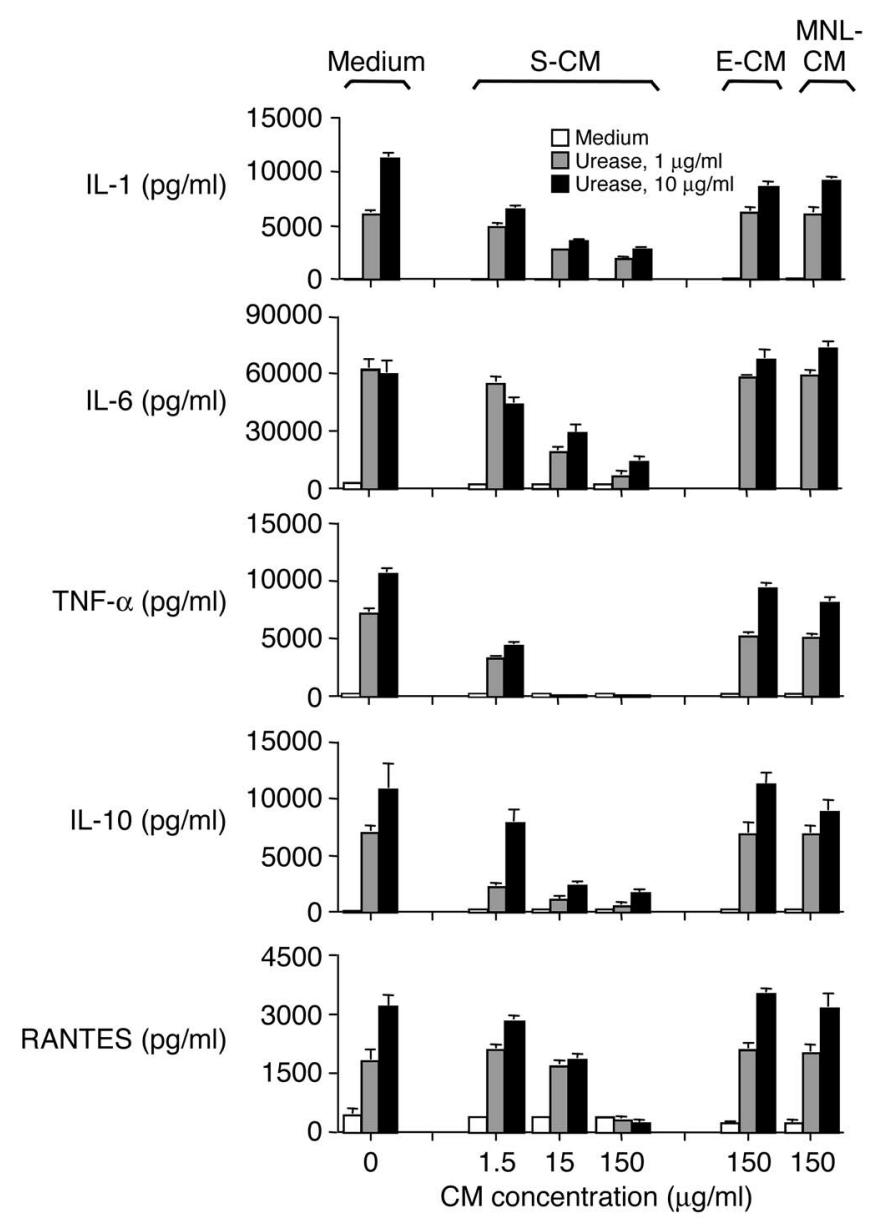

To understand the relationship between $\mathrm{S}$-CM-induced downregulation of IL-1, IL- 6 , IL-10, and TNF- $\alpha$, and the upregulation of TGF- $\beta$, TGF- $\beta$-blocking studies were performed. Anti-TGF- $\beta$ Abs reversed the ability of S-CM to inhibit LPS-stimulated monocyte TNF- $\alpha$ production and enhanced TNF- $\alpha$ mRNA expression in a dose-dependent manner (Figure $7 \mathrm{~B})$, implicating TGF- $\beta$ as a mediator of S-CM inhibitory activity. Similarly, anti-TGF- $\beta$ Abs blocked the ability of S-CM to inhibit phagocytosis-stimulated cytokine production (data not shown). Thus, the downregulatory action of S-CM appeared to be due, at least in part, to S-CM TGF- $\beta$ induction of monocytes to release TGF- $\beta$, which then downregulated monocyte production of proinflammatory cytokines.

To provide more direct evidence that mucosa-derived TGF- $\beta$ downregulates monocyte cytokine production, we cultured explants of jejunal mucosa (after submucosa removal) and determined whether the tissue culture supernatant inhibited monocyte TNF- $\alpha$ production. As shown in Figure 8A, preincubation of monocytes with supernatant from cultured jejunal explants caused a dose-dependent decrease in LPS-induced TNF- $\alpha$ production and a reciprocal increase in TGF- $\beta$ protein, further implicating TGF- $\beta$ as an inhibitor of monocyte cytokine production. In addition, blocking experiments showed that the addition of anti-TGF- $\beta$ Abs reversed the ability of culture supernatant from jejunal mucosa to block monocyte TNF- $\alpha$ production (Figure 8B). Thus, TGF- $\beta$ released by both jejunal

\section{Figure 5}

S-CM downregulation of monocyte cytokine production. Blood monocytes were incubated in the presence or absence of $\mathrm{H}$. pylori urease and either S-CM, E-CM, or MNL-CM at the indicated concentrations for 24 hours, and supernatants were assayed for IL-1, IL-6, TNF- $\alpha, \mathrm{IL}-10$ and RANTES. Values are mean $+\operatorname{SD}(n=7)$.

lamina propria stroma and intact jejunal mucosa inhibited monocyte TNF- $\alpha$ production.

Source of the mucosal TGF- $\beta$. Since blocking studies using lamina propria stroma and ex vivo jejunal tissue implicated TGF- $\beta$ as a mediator of the inhibition of monocyte cytokine production, we performed studies to identify the source of the TGF- $\beta$. In serial sections of jejunum, TGF- $\beta$-staining cells were detected in both the lamina propria and epithelium. The lamina propria TGF- $\beta^{+}$ cells were scattered throughout the lamina propria (Figure 9A) and stained for the mast cell marker c-kit (Figure 9B), but not the macrophage marker HAM56 (Figure 9C). In addition, the $\mathrm{TGF}-\beta^{+} / \mathrm{c}-\mathrm{kit}^{+}$lamina propria cells stained for chymase, another mast cell marker (data not shown). These findings indicate that mast cells, not macrophages, were a local source of TGF- $\beta$. The TGF- $\beta^{+}$cells in the epithelium (Figure 9D) were located mainly at the villus tip, displayed epithelial cell morphology (goblet cells did not stain for TGF- $\beta$ ), and stained predominantly in the basal region of the cells. TGF- $\beta$ protein was present in S-CM but not E-CM or MNL-CM (Figure 9E), and RT-PCR analysis revealed TGF- $\beta$ transcripts in stroma and epithelial cells, but not macrophages. TGF- $\beta$ was not detected in the E-CM, likely due to the short viability (less than 12 hours) of the epithelial cells ex vivo. These findings implicate intestinal epithelial cells and lamina propria mast cells as a source of mucosal TGF- $\beta$ and suggest that TGF- $\beta$ released by epithelial and mast cells in vivo binds the lamina propria extracellular matrix and in vitro is released into the S-CM.

\section{Discussion}

We report that resident macrophages isolated from the lamina propria of normal human intestine are phenotypically and functionally distinct from blood monocytes. In sharp contrast to blood monocytes, intestinal macrophages lack innate response receptors, including the receptors for LPS, IgA, IgG, CR3, and CR4; growth factor receptors for IL-2 and IL-3; and the integrin LFA-1. Also in marked contrast to monocytes, intestinal macrophages stimulated with an array of proinflammatory agents do not produce IL-1, IL-6, IL-10, IL-12, RANTES, TNF- $\alpha$, or TGF- $\beta$. Macrophages release IL-8, but approximately four logs less than stimulated blood monocytes. The downregulated production of cytokines is not restricted to CD14-mediated responses, since intestinal macrophages also did not produce cytokines in response to a wide array of other potent proinflammatory stimuli, including phagocytosis. Finally, intestinal stromal cell products induced in monocytes an intestinal macrophage phenotype and cytokine profile. TGF- $\beta$, which appeared to be produced by intestinal epithelial cells and lamina propria mast cells, was a key stromal product that inhibited monocyte cytokine production. The presence of TGF- $\beta$ protein in the media of cultured stroma and jejunal explants suggested that TGF- $\beta$ released by the epithelial and mast cells bound to the lamina propria extracellular matrix and, after its release 
A

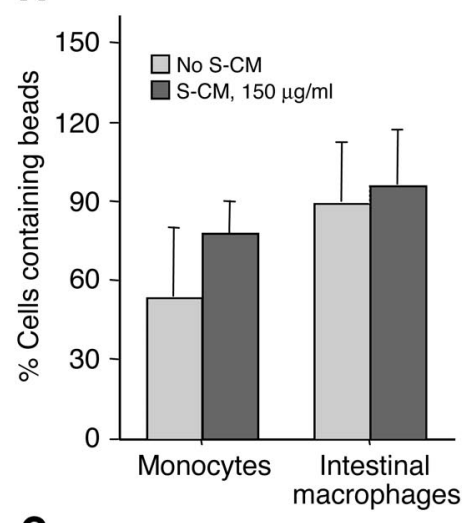

C

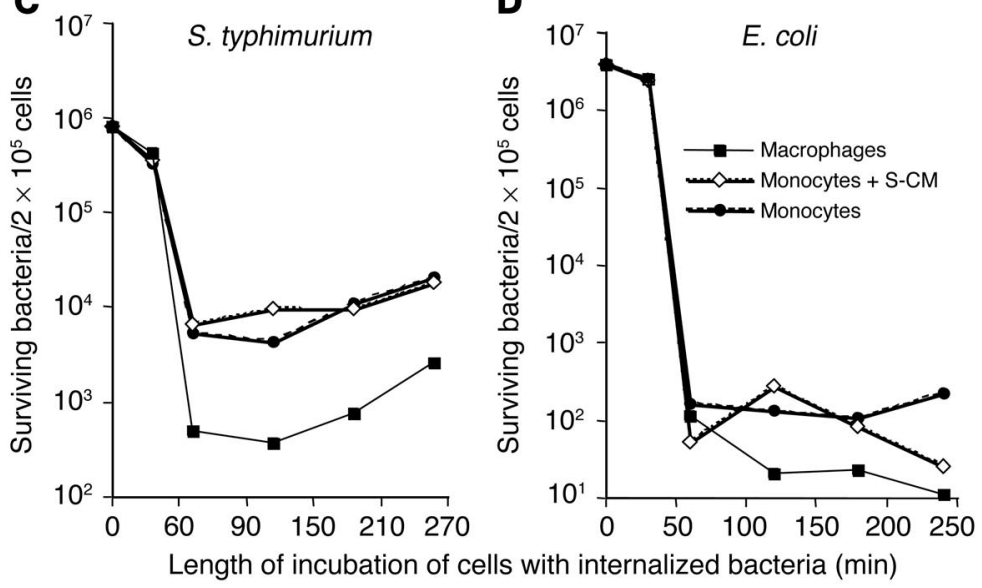

B

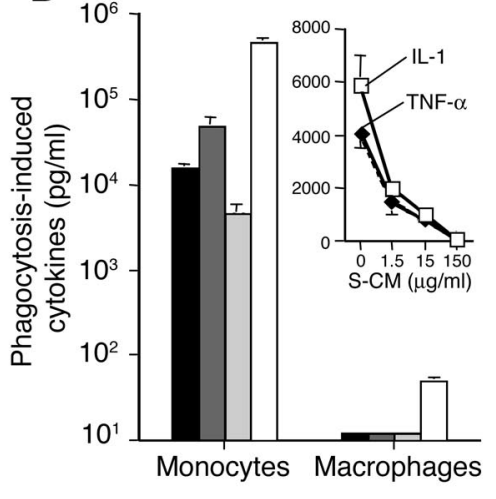

D

\section{Figure 6}

Phagocytic and bacteriocidal activity of blood monocytes and intestinal macrophages. (A) Blood monocyte and intestinal macrophage phagocytosis in the absence or presence of S-CM. Phagocytosis was measured as the percentage of cells that contained FITC-labeled beads after 1-hour incubation. Values are mean + SD $(n=3)$. (B) Phagocytosisinduced cytokine production by blood monocytes and intestinal macrophages. Blood monocytes and intestinal macrophages were incubated with latex beads for 2 hours, washed, cultured for 24 hours, and the supernatants assayed for IL-1 (black bars), IL-6 (dark gray bars), TNF- $\alpha$ (light gray bars), and IL-8 (white bars). Values are mean + SD $(n=4)$. Inset: S-CM downregulation of phagocytosisinduced cytokine release by monocytes. Blood monocytes were incubated with latex beads in the absence or presence of increasing concentrations of S-CM, washed, and cultured for 24 hours in the same concentrations of S-CM. Culture supernatants were harvested and assayed for IL-1 and TNF- $\alpha$. Values are mean + SD $(n=3)$. (C and D) Killing of Gram-negative bacteria by blood monocytes and intestinal macrophages. Intestinal macrophages, blood monocytes, and blood monocytes plus S-CM $500 \mu \mathrm{g} / \mathrm{ml}$ $\left(2 \times 10^{5}\right.$ cells $\left./ 250 \mu \mathrm{l}\right)$ were incubated with $(\mathbf{C})$ S. typhimurium $\left(8 \times 10^{6} \mathrm{CFU} / \mathrm{ml}\right)$ or (D) E. coli $\left(4 \times 10^{6} \mathrm{CFU} / \mathrm{ml}\right)$, and intracellular killing was determined as described in Methods. The 3 populations of cells killed the vast majority of the bacteria within 30-60 minutes. and activation, induced the differentiation of proinflammatory monocytes into noninflammatory intestinal macrophages.

Blood monocytes populate the macrophage component of intestinal mononuclear cells $(9,17,18)$, yet monocytes and intestinal macrophages are phenotypically and functionally distinct. Our finding that factors released by intestinal stroma induce blood monocytes to differentiate into an intestinal macrophage phenotype and downregulate monocyte cytokine production, but not phagocytic or bacteriocidal activity, indicates that lamina propriaderived factors may play a key role in monocyte differentiation into intestinal macrophages. In related studies $(19,20)$, we have shown that intestinal macrophages lack CCR5, a coreceptor on monocytes for R5 HIV-1 viruses, and that S-CM is a potent downregulator of monocyte CCR5 expression (G. Meng, unpublished data). Thus, S-CM downregulates an array of important receptors on blood monocytes. Interestingly, low numbers of intestinal macrophages expressed CD36, and S-CM reduced CD36 expression on blood monocytes. The presence of low levels of CD36, a class B scavenger receptor, on intestinal macrophages is consistent with the ability of the cells to phagocytose apoptotic cells (L.E. Smythies, unpublished data) (21).

Consistent with their central role in host defense against microorganisms and noxious molecules that have breached the epithelium, intestinal macrophages are avidly phagocytic for live microorganisms, as shown here, and inert material $(4,5)$. Whereas phagocytosis itself caused monocytes to produce proinflammatory cytokines, phagocytosis did not stimulate intestinal macrophages to release cytokines. Along with phagocytic activity, intestinal macrophages show strong and rapid bacteriocidal activity for S. typhimurium and E. coli. Thus, intestinal macrophages display inflammatory anergy but retain avid phagocytic and bacteriocidal activity.

The ability of anti-TGF- $\beta$ Abs to block S-CM-induced downregulation of cytokine production provides strong evidence that TGF- $\beta$ mediates, in part, this downregulation. Immunohistochemical, RT-PCR, and ELISA analyses implicate epithelial cells and mast cells, but not intestinal macrophages, as local sources of TGF- $\beta$ in vivo. TGF- $\beta$ is a potent suppressor of many monocyte functions (14-16), except phagocytic activity (12). TGF- $\beta$ may affect its inhibitory activity directly or through the induction of TGF- $\beta$ by newly recruited monocytes. In this regard, TGF- $\beta$ is itself a potent autocrine inducer of TGF- $\beta$ by both peripheral blood monocytes $(22,23)$ and intestinal epithelial cells $(24,25)$. Thus, the findings presented here suggest the following sequence of events. Latent TGF- $\beta$ produced by mucosal epithelial cells and mast cells is released into the lamina propria where it binds to lamina propria stroma, consistent with studies showing TGF- $\beta$ bound to extracellular matrix (26). After release in response to local factors, possibly mast cell chymase, and then activation by local proteases (27), the TGF- $\beta$ and possibly other stromal cell factors act on monocytes newly recruited to the lamina propria to induce differentiation of these highly proinflammatory cells into noninflammatory macrophages.

To study the role of TGF- $\beta$ in mucosal homeostasis in mice, we examined TGF- $\beta^{-/-}$mice for CD14 expression in intestinal mucosa. The small intestine in 3 -week-old TGF- $\beta^{-/-}$and TGF- $\beta^{+/+}$ 
A
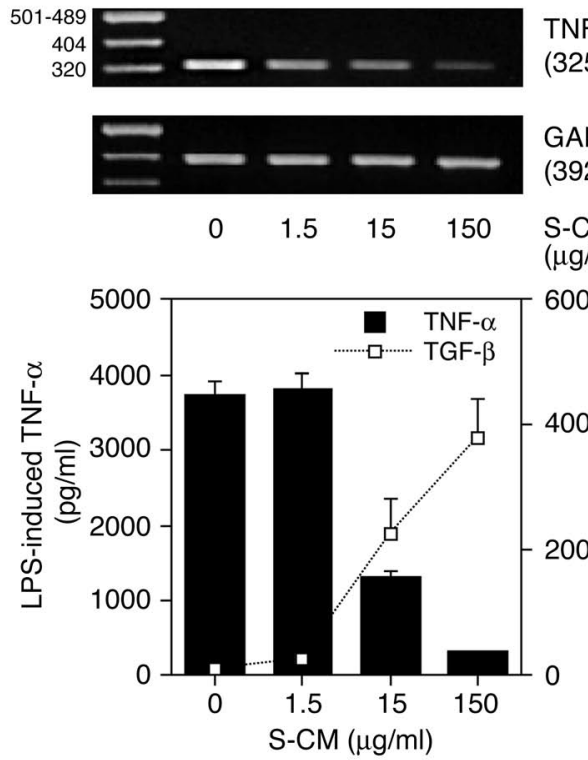

B
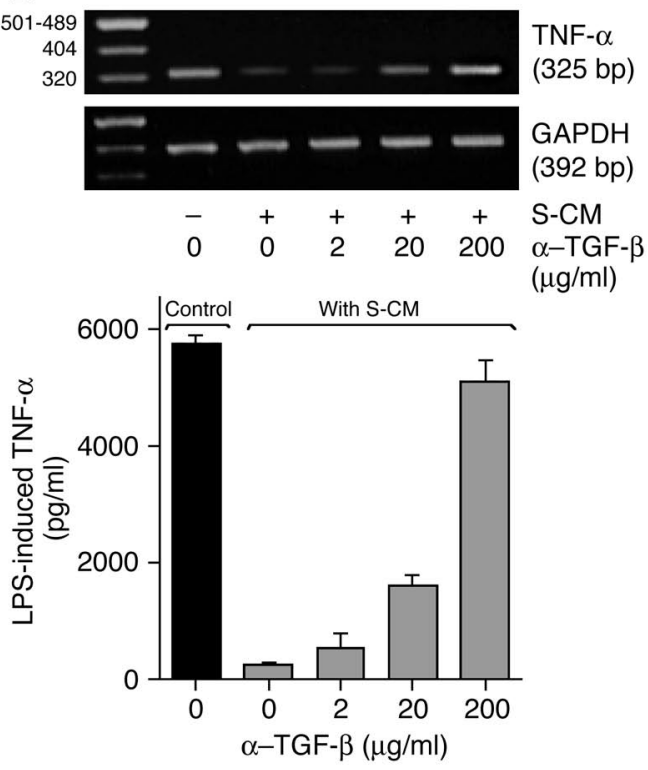

TNF- $\alpha$ (325 bp)

GAPDH (392 bp)

$\mathrm{S}-\mathrm{CM}$ $(\mu \mathrm{g} / \mathrm{ml})$ 600

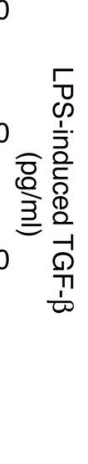

\section{Figure 7}

S-CM TGF- $\beta$ downregulates monocyte cytokine production. (A) S-CM induces decreased TNF- $\alpha$ and increased TGF- $\beta$ release by monocytes. Blood monocytes were incubated in the absence or presence of increasing concentrations of S-CM for 1 hour and then for an additional 24 hours with LPS $(1 \mu \mathrm{g} / \mathrm{ml})$. The harvested supernatants were analyzed for TNF- $\alpha$ and TGF- $\beta$ protein. Values are mean + SD $(n=3)$. Parallel cultures of similarly treated monocytes (2 hours) were analyzed by RT-PCR for TNF- $\alpha$ and GAPDH mRNA. (B) TGF- $\beta$ Abs block S-CM-induced downregulation of LPS-stimulated TNF- $\alpha$ release by monocytes. Blood monocytes were incubated with increasing concentrations of anti-TGF- $\beta$ Abs and S-CM $(150 \mu \mathrm{g} / \mathrm{ml})$ and stimulated with LPS $(1 \mu \mathrm{g} / \mathrm{ml})$ for 24 hours. Supernatants were analyzed for TNF- $\alpha$ protein. Neither anti-TGF- $\beta$ nor anti-IL-10 Abs (200 $\mu \mathrm{g} / \mathrm{ml}$ each) in the absence of S-CM significantly affected monocyte production of TNF- $\alpha$ or IL-1. Values are mean + SD $(n=3)$. Parallel cultures were analyzed for TNF- $\alpha$ and GAPDH mRNA as in A.

C57BL/6 mice contained numerous $\mathrm{F} 4 / 80^{+}$macrophages that did not express CD14, although $\mathrm{F} 4 / 80^{+}$splenic macrophages from the same animals did (data not shown). These data suggest that CD14 expression is downregulated in both human and murine mucosa, but in mice, factors other than or in addition to TGF- $\beta$ contribute to the downregulation. Nevertheless, the profound mucosal inflammation and early morbidity of TGF- $\beta^{-/-}$mice (28) suggest a crucial role for TGF- $\beta$ in intestinal homeostasis in mice as well as in humans.

In addition to TGF- $\beta$, IL-10 is a potent inhibitor of cytokine production by activated monocytes (29), possibly by blockade of NF$\kappa \mathrm{B}$ activation through inhibition of both IкB kinase activity and NF- $\kappa B$ DNA-binding activity (30). Moreover, the role of IL-10 in downmodulating mucosal inflammation is well documented (31, 32). Thus, although IL-10 undoubtedly contributes to the absence of inflammation in normal intestinal mucosa in vivo, the in vitro system of reconstituted mucosa described here showed that TGF- $\beta$ also likely participates in modulating mucosal inflammation.

Resident intestinal macrophages, unlike blood monocytes, display constitutive TGF- $\beta$-induced Smad activation, reflected in elevated levels of Smad p2/3 and Smad 4 and a reduced level of inhibitory Smad7, despite the cells' inability to produce TGF- $\beta$ (L.E. Smythies, unpublished data). During inflammation, increased TGF- $\beta$ production by newly recruited, activated inflammatory cells would promote matrix replacement at the site of injury, and excess TGF- $\beta$ production would promote fibrosis, as in Crohn

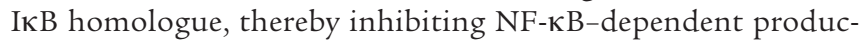
tion of proinflammatory cytokines but not TGF- $\beta$ production; TGF- $\beta$ mRNA and protein are actually increased in ASFV-infected macrophages (36). S-CM may affect discordant cytokine regulation via an analogous mechanism, namely, blockade of NF-кB-mediated signal transduction. We recognize that other factors such as the recently identified thymic stromal lymphopoietin (TSLP) (37) may also be involved, since S-CM (and TSLP) downregulates monocytederived IL-10, which is not NF- $\mathrm{KB}$ mediated (38).

The inflammatory anergy of intestinal macrophages, reflected in the cells' reduced expression of innate response receptors and downregulated production of cytokines, indicates a potential mechanism for the absence of inflammation in normal intestinal mucosa despite the close proximity of immunostimulatory bacteria and LPS. In contrast, during inflammatory processes such as inflammatory bowel disease, approximately one third of the mononuclear phagocytes in the mucosa appear to be newly recruited blood monocytes $(9,17,39)$. In inflamed mucosa, suppressive stromal factors may no longer be released or lose their ability to drive recruited monocytes toward a macrophage profile. Thus, the findings reported here support the concept that blood monocytes recruited to the intestinal mucosa encounter stromal-derived factors such as TGF- $\beta$, which downregulate proinflammatory but not phagocytic or bacteriocidal activity. The resultant inflammatory anergy serves to limit mucosal inflammation in normal intestinal mucosa, 

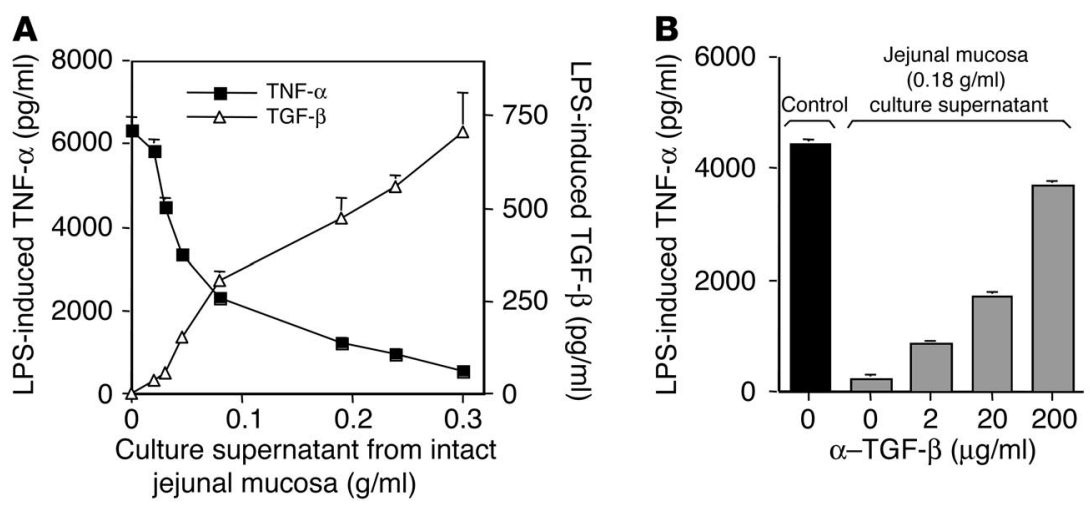

Figure 8

Jejunal tissue TGF- $\beta$ downregulates monocyte cytokine production. (A) Culture supernatants from explants of jejunal mucosa cause dose-dependent downregulation of TNF- $\alpha$ and reciprocal upregulation of TGF- $\beta$ release by monocytes. Monocytes were incubated with culture supernatant from explants of jejunal mucosa of increasing wet weight for 1 hour and then for 24 hours with LPS $(1 \mu \mathrm{g} / \mathrm{ml})$. Culture supernatants were harvested and analyzed for TNF- $\alpha$ and TGF- $\beta$ protein. Values are mean \pm SD $(n=2)$. (B) TGF- $\beta$ Abs reverse the ability of jejunal mucosa culture supernatant to inhibit monocyte TNF- $\alpha$ release. Monocytes were incubated with increasing concentrations of anti-TGF- $\beta$ Abs and jejunal mucosa culture supernatant and stimulated with LPS $(1 \mu \mathrm{g} / \mathrm{ml})$ for 24 hours. Supernatants were analyzed for TNF- $\alpha$. Values are mean \pm SD $(n=2)$.

whereas the loss or dysregulation of macrophage inflammatory anergy may promote the inflammation associated with inflammatory bowel disease.

\section{Methods}

Intestinal macrophages and blood monocytes. Intestinal macrophages were isolated by enzyme digestion of intestinal tissue sections and purified by counterflow centrifugal elutriation, as described previously (4, 5, 19, 40, 41). Briefly, sections of normal human jejunum obtained (with approval of the Institutional Review Board of the University of Alabama at Birmingham) from patients undergoing gastrojejunostomy or healthy organ transplantation donors were dissected into mucosa and submucosa. The mucosa was rinsed in $\mathrm{Ca}^{++}$- and $\mathrm{Mg}^{++}$-free PBS and washed in HBSS plus DTT $(200 \mu \mathrm{g} / \mathrm{ml})$ to remove residual mucus and then in HBSS containing
$0.2 \mathrm{M}$ EDTA plus $10 \mathrm{mM}$ 2-mercaptoethanol to remove the epithelium. Sections then were minced and treated with $75 \mu \mathrm{g} / \mathrm{ml}$ neutral protease Dispase (grade I, specific activity $>6 \mathrm{U} / \mathrm{mg}$ with $<0.01 \mathrm{ng} /$ $\mathrm{ml}$ endotoxin by Limulus amebocyte lysate assay; Boehringer Mannheim $\mathrm{GmbH}$ ) to release the lamina propria mononuclear cells. Macrophages were purified from the mononuclear cell population by gradient sedimentation followed by elutriation (40). Blood monocytes were purified from healthy donors by elutriation and treated with Dispase according to the macrophage isolation protocol so that both intestinal macrophages and blood monocytes were treated similarly. Cells were fixed, prepared, and examined by light and electron microscopy, as previously described (4). The cells isolated by these techniques were routinely more than $98 \%$ viable by propidium iodide staining; morphologic and ultrastructural features of the intestinal cells showed they were macrophages $(4,5)$. The absence of detectable CD3, CD20, CD69, CD34, CD83, and CD103 on the purified cell populations by flow cytometry (see above) confirmed the absence of contaminating T, B, and NK cells, DCs, and intestinal lymphocytes (Table 1). Furthermore, culture of intestinal macrophages with optimal concentrations of GM-CSF, IL-4, and TNF- $\alpha$ (42) did not induce the expression of DC markers or morphology. In addition, the cells were more than $95 \%$ esterase positive and avidly phagocytic $(4,5)$. Thus, the elutriated populations of intestinal macrophages were more than $98 \%$ pure.

Mucosal cell-CM. Purified lamina propria mononuclear cells $\left(10^{6} \mathrm{cells} / \mathrm{ml}\right)$ (4), cell-depleted lamina propria stroma ( $1 \mathrm{~g}$ wet weight stromal tissue per milliliter) (4), and epithelial cells $\left(10^{6}\right.$ cells $\left./ \mathrm{ml}\right)(43)$ were cultured in RPMI for 24 hours. Lamina propria MNL-CM, E-CM, and S-CM were harvested, sterile filtered (0.2- $\mu \mathrm{m}$ Syringe Filter; Corning Inc.), and frozen at $-70^{\circ} \mathrm{C}$. Supernatant was also obtained from 24-hour cultures of intact jejunal mucosa. CMs did not alter blood monocyte or intestinal macrophage viability during incubation for as long as 4 days as assessed by propidium iodide uptake. Endotoxin, protein, and protease content were determined by commercially available ELISA assays.

\section{Figure 9}

Detection of TGF- $\beta$. (A-D) TGF- $\beta$ was detected (arrows) in (A) lamina propria cells that stained with (B) mast cell marker c-kit but not (C) macrophage marker HAM56 and in (D) epithelial cells (magnification, $\times 40$ ). (E) Soluble TGF- $\beta$ protein was detected in S-CM but not E-CM or MNL-CM (each normalized to $2 \mathrm{mg} / \mathrm{ml}$ total protein), which were generated from lamina propria stroma, intestinal epithelial cells, and intestinal mononuclear cells, respectively (mean values for CMs from 3 separate donors). (F) TGF- $\beta$ mRNA was present in whole tissue, stroma and epithelial cells, but not lamina propria (L.P.) macrophages from a representative donor $(n=3)$. Insets show a TGF- $\beta^{+}(\mathbf{A}), \mathrm{c}^{-\mathrm{kit}^{+}}(\mathbf{B})$, and HAM56- $^{-}(\mathbf{C})$ cell at high magnification $(\times 100)$.
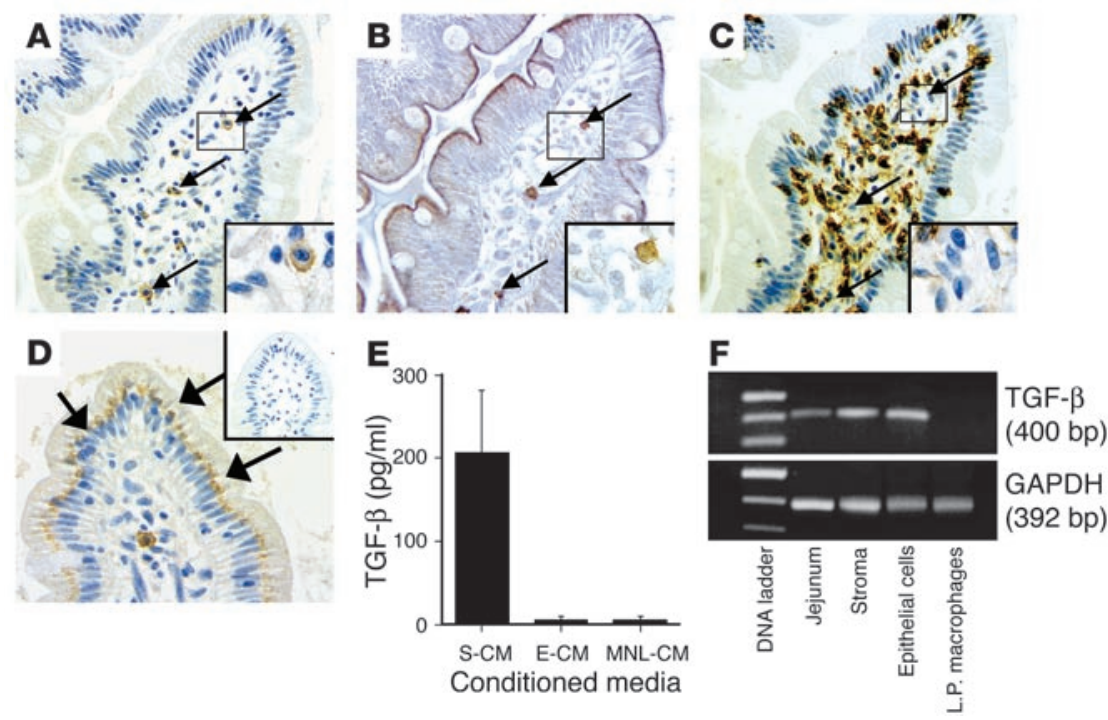
Immunohistochemical analysis. Serial sections $(5 \mu \mathrm{m})$ of formalin-fixed, paraffin-embedded intestinal tissue were placed on lysine-coated slides, deparaffinized, and rehydrated. Antigen retrieval was achieved by immersion of the sections in $10 \mathrm{mM}$ sodium citrate buffer, $\mathrm{pH} 6.0$, heated to $95^{\circ} \mathrm{C}$ for 5 minutes, and allowed to cool for 20 minutes. Slides were transferred to water (5 minutes), then treated with $\mathrm{H}_{2} \mathrm{O}_{2}$ ( $3 \%, 30$ minutes) to block endogenous peroxidase, rinsed in PBS (5 minutes), blocked (casein protein, 60 minutes; DAKO Corp.), rinsed again in PBS, and then incubated with either rabbit anti-human TGF- $\beta(0.05 \mathrm{mg} / \mathrm{ml}$; Santa Cruz Biotechnology Inc.), mouse mAb to the macrophage marker HAM56 $(0.05 \mathrm{mg} / \mathrm{ml}$, 10 minutes; DAKO Corp.), mouse mAb to the mast cell marker c-kit (anti-human collagen 4; Ventana Medical Systems Inc.), or irrelevant isotype-matched Ab. Sections then were washed in PBS (5 minutes), incubated with anti-mouse and anti-rabbit polymer (30 minutes, HRP; DAKO Corp.), followed by diaminobenzidene-positive $\mathrm{AB}^{+}$substrate-chromogen solution (DAKO Corp.) and counterstained with H\&E.

Flow cytometry and Abs. To evaluate cell purity and phenotype, intestinal macrophages and blood monocytes $\left(2 \times 10^{5}\right)$ were incubated with optimal concentrations of PE-CD3, PE-CD11a, PE-CD11b, PE-CD11c, PE-CD13, PE-CD14, FITC-CD16, PE-CD18, PE-CD20, PE-CD25, FITC-CD32, PECD33, PE-CD34, FITC-CD36, FITC-CD64, FITC-CD69, PE-CD89, FITCCD103, PE-CD123, and FITC-HLA-DR (BD Biosciences - Pharmingen), and PE-CD83 (Immunotech) or control PE- or FITC-labeled irrelevant mAbs of the same isotype. Blood monocytes were also analyzed by flow cytometry after incubation in media plus S-CM, E-CM, or MNL-CM, and in S-CM plus Protease Inhibitor Cocktail (Roche Molecular Biochemicals) as specified by the manufacturer. After staining, the cells were washed, fixed in $1 \%$ paraformaldehyde, and analyzed by flow cytometry. Data were analyzed with CellQuest software (BD).

Macrophage function and cytokine production assays. Intestinal macrophages and blood monocytes $\left(2 \times 10^{6}\right.$ cells $\left./ \mathrm{ml}\right)$ were cultured in RPMI for 2 days and then incubated in triplicate wells for 24,48 , and 72 hours in RPMI with $10 \%$ human $\mathrm{AB}$ serum $\left(\mathrm{RPMI}^{+}\right.$; Atlanta Biologicals Inc.) in the absence or presence of LPS ( 1 and $10 \mu \mathrm{g} / \mathrm{ml}$; Sigma-Aldrich), PMA (40 ng/ml; Sigma-Aldrich), H. pylori urease (1 and $10 \mu \mathrm{g} / \mathrm{ml}$; Oravax Inc.), IFN- $\gamma$ (100 U; R\&D Systems Inc.), for 5 or 24 hours, followed by LPS ( 1 and $10 \mu \mathrm{g} / \mathrm{ml}$ ) or HK S. aureus (a kind gift from J.D. Chiche and J.P. Mira, Institut Cochin de Genetique Moleculaire, Paris, France). The levels of IL-1, IL-6, IL-8, TNF- $\alpha$, IL-10, IL-12, TGF- $\beta$, and RANTES in culture supernatants were measured by ELISA (R\&D Systems Inc.). The presence of intracellular cytokines in intestinal macrophages and monocytes cultured for 24 hours was determined by flow cytometry as previously described (43), using mouse mAbs to IL-1, IL-6, IL-8, and TNF- $\alpha$ (BD Biosciences - Pharmingen).

Phagocytosis. Intestinal macrophages, blood monocytes, and blood monocytes in the presence of S-CM were incubated with FITC-labeled microspheres (10 microspheres/cell for 2 hours at $37^{\circ} \mathrm{C}$; Polysciences Inc.) and then analyzed by FACS for intracellular beads, as previously described $(4,5)$. Parallel populations of cells were allowed to phagocytose an equivalent number of beads, were washed, and after an additional 24-hour culture, phagocytosis-induced cytokines released into the culture supernatant were measured as described above.

Bacteriocidal assay. Intestinal macrophages, blood monocytes in the presence of S-CM $(500 \mu \mathrm{g} / \mathrm{ml})$, and blood monocytes in the absence of S-CM (each population $2 \times 10^{5}$ cells $/ 250 \mu \mathrm{l}$ ) were incubated in RPMI (without antibiotics or serum) at $37^{\circ} \mathrm{C}$ with S. typhimurium LT2L $\left(8 \times 10^{6} \mathrm{CFU} / \mathrm{ml}\right)$ or E. coli MC4100 $\left(4 \times 10^{6} \mathrm{CFU} / \mathrm{ml}\right)$ for 60 minutes or 30 minutes, respectively. After incubation with the bacteria, cells were washed and resuspended in RPMI plus gentamycin $(200 \mu \mathrm{g} / \mathrm{ml})$ to kill any remaining extracellular, but not intracellular, bacteria. Duplicate aliquots of cells were quickly harvested and, at 30-minute intervals thereafter, washed in PBS, lysed in $1 \%$ saponin/PBS, and plated in serial dilutions on LB agar plates (SigmaAldrich). After overnight incubation, bacterial colonies were enumerated to determine the number of surviving intracellular bacteria.

RT-PCR. RNA was isolated from blood monocytes incubated for 3 hours in the absence or presence of S-CM and anti-TGF- $\beta$ mAbs (R\&D Systems Inc.) and from intact jejunal tissue, lamina propria stroma, intestinal epithelial cells, and lamina propria macrophages. After reverse transcription, the resultant cDNA $(5 \mu \mathrm{l})$ was amplified in a $50-\mu \mathrm{l}$ reaction containing $0.25 \mu \mathrm{l} \mathrm{Taq}$ polymerase (5 U/ml; PerkinElmer Cetus Gene Amp PCR system; PerkinElmer Inc.), $4 \mu \mathrm{l} \mathrm{dNTPs} \mathrm{(2.5} \mathrm{mmol/l;} \mathrm{Promega} \mathrm{Corp.),} 2 \mu \mathrm{l} \mathrm{MgCl} 2$ ( $25 \mathrm{mmol} / \mathrm{l}), 5 \mu \mathrm{l}$ $10 \times$ PCR reaction buffer, and $2.5 \mu$ of primers for TNF- $\alpha$ (5), TGF- $\beta$ (44), or GAPDH (5). The reaction mixture was amplified for TNF- $\alpha$ (denaturation: $95^{\circ} \mathrm{C}$ for 1 minute; annealing: $55^{\circ} \mathrm{C}$ for 30 seconds; extension: $72^{\circ} \mathrm{C}$ for 1 minute, 35 cycles); TGF- $\beta$ (denaturation: $94^{\circ} \mathrm{C}$ for 1 minute; annealing: $57^{\circ} \mathrm{C}$ for 1 minute; extension $72^{\circ} \mathrm{C}$ for 2 minutes, 35 cycles); and GAPDH (denaturation: $95^{\circ} \mathrm{C}$ for 1 minute; annealing: $60^{\circ} \mathrm{C}$ for 2 minutes; extension: $72^{\circ} \mathrm{C}$ for 3 minutes, 25 cycles); and the products were detected by PAGE.

\section{Acknowledgments}

This work was supported by the NIH (grants DK-47322, DK-54495, HD-41361, DK-64400, and DE-16005), the Crohn's and Colitis Foundation of America, and the Research Service of the Department of Veterans Affairs. The authors thank Teresa Leath for help with the recruitment of donors and Kathleen Peters for help with manuscript preparation.

Received for publication June 17, 2003, and accepted in revised form October 19, 2004.

Address correspondence to: Phillip D. Smith, Department of Medicine (Gastroenterology), 633 Zeigler Research Building, 703 South 19th Street, Birmingham, Alabama 35294, USA. Phone: (205) 975-9254; Fax: (205) 934-8493; E-mail: PDSmith@UAB.edu.
1. Lee, S.H., Starkey, P.M., and Gordon, S. 1985. Quantitative analysis of total macrophage content in adult mouse tissues: Immunochemical studies with monoclonal Ab F4/80. J. Exp. Med. 161:475-489.

2. Brandtzaeg, P. 1989. Overview of the mucosal immune system. Curr. Top. Microbiol. Immunol. 146:13-25.

3. Ulevitch, R.J., and Tobias, P.S. 1995. Receptordependent mechanisms of cell stimulation by bacterial endotoxin. Ann. Rev. Immunol. 13:437-457.

4. Smith, P.D., et al. 1997. Isolation and purification of CD14-negative mucosal macrophages from normal human small intestine. J. Immunol. Meth 202:1-11.

5. Smith, P.D., et al. 2001. Intestinal macrophages lack CD14 and CD89 and consequently are downregulated for LPS- and IgA-mediated activities. J. Immunol. 167:2651-2656.

6. Grimm, M.C., Pavli, P., and Doe, W.F. 1995. Evidence for a CD14 ${ }^{+}$population of monocytes in inflammatory bowel disease mucosa - implications for pathogenesis. Clin. Exp. Immunol. 100:291-297.

7. Rogler, G., et al. 1998. Isolation and phenotypic characterization of colonic macrophages. Clin. Exp. Immunol. 112:205-215.

8. Herzyk, D.J., Allen, J.N., Marsh, C.B., and Wewers, M.D. 1992. Macrophage and monocyte IL-1 $\beta$ regulation differs at multiple sites. Messenger RNA expression, translation, and post-translational processing. J. Immunol. 149:3052-3058.
9. Rugtveit, J., Brandtzaeg, P., Halstensen, T.S., Fausa, O., and Scott, H. 1994. Increased macrophage subset in inflammatory bowel disease: apparent recruitment from peripheral blood monocytes. Gut. 35:669-674.

10. Harris, P.R., Mobley, H.L., Perez-Perez, G.I., Blaser, M.J., and Smith, P.D. 1996. Helicobacter pylori urease is a potent stimulus of mononuclear phagocyte activation and inflammatory cytokine production. Gastroenterology. 111:419-425.

11. Mai, U.E., et al. 1991. Soluble surface proteins from Helicobacter pylori activate monocytes/macrophages by lipopolysaccharide-independent mechanism. J. Clin. Invest. 87:894-900.

12. Smith, P.D., Smythies, L.E., and Wahl, S.M. 2001. Macrophage effector function. In Clinical immunology. 
R.R. Rich, T.A. Fleisher, W.T. Sherarer, B. Kotzin, and H.W.J. Schroeder, editors. Harcourt Health Sciences. London, United Kingdom. 19.11-19.19.

13. Finlay, B.B., and Cossart, P. 1997. Exploitation of mammalian host cell functions by bacterial pathogens. Science. 276:718-725.

14. Tsunawaki, S., Sporn, M.B., Ding, A., and Nathan, C. 1988. Deactivation of macrophages by transforming growth factor- $\beta$. Nature. 334:260-262.

15. Wahl, S.M. 1994. Transforming growth factor $\beta$ : the good, the bad and the ugly. J. Exp. Med. 180:1587-1590.

16. Letterio, J.J., and Roberts, A.B. 1998. Regulation of immune responses by TGF- $\beta$. Annu. Rev. Immunol. 16:137-161.

17. Grimm, M.C., et al. 1995. Direct evidence of monocyte recruitment to inflammatory bowel disease mucosa. J. Gastroenterol. Hepatol. 10:387-395.

18. Burgio, V.T., Fais, S., Boirivant, M., Perrone, A., and Pallone, F. 1995. Peripheral monocyte and naive T-cell recruitment and activation in Crohn's disease. Gastroenterology. 109:1029-1038.

19. Li, L., Meng, G., Graham, M.F., Shaw, G.M., and Smith, P.D. 1999. Intestinal macrophages display reduced permissiveness to human immunodeficiency virus 1 and decreased surface CCR5. Gastroenterology. 116:1043-1053.

20. Meng, G., et al. 2000. Lamina propria lymphocytes, not macrophages, express CCR5 and CXCR4 and are likely target cell for human immunodeficiency virus type 1 in the intestinal mucosa. J. Infect. Dis. 182:785-791.

21. Savill, J., Hogg, N., Ren, Y., and Haslett, C. 1992. Thrombospondin cooperates with CD36 and the vitronectin receptor in macrophage recognition of neutrophils undergoing apoptosis. J. Clin. Invest. 90:1513-1522.

22. McCartney-Francis, N., Mizel, D., Wong, H., Wahl, L., and Wahl, S. 1990. TGF- $\beta$ regulates production of growth factors and TGF- $\beta$ by human peripheral blood monocytes. Growth Factors. 4:27-35.

23. Blobe, G.C., Schiemann, W.P., and Lodish, H.F. 2000. Role of transforming growth factor $\beta$ in human disease. N. Engl. J. Med. 342:1350-1358.

24. Barnard, J.A., Beauchamp, R.D., Coffey, R.J., and Moses, H.L. 1989. Regulation of intestinal epithelial cell growth by transforming growth factor type $\beta$. Proc. Natl. Acad. Sci. U. S. A. 86:1578-1582.

25. Suemori, S., Ciacci, C., and Podolsky, D.K. 1991. Regulation of transforming growth factor expression in rat intestinal epithelial cell lines. J. Clin. Invest. 87:2216-2221.

26. Ashcroft, G.S., et al. 2000. Secretory leukocyte protease inhibitor mediates non-redundant functions necessary for normal wound healing. Nat. Med. 6:1147-1153.

27. Saharinen, J., Hyytiäinen, M., Taipale, J., and Keski-Oja, J. 1999. Latent transforming growth factor- $\beta$ binding proteins (LTBPs) - structural extracellular matrix proteins for targeting TGF- $\beta$ action. Cytokine Growth Factor Rev. 10:99-117.

28. Shull, M.M., et al. 1992. Targeted disruption of the mouse transforming growth factor- $\beta 1$ gene results in multifocal inflammatory disease. Nature. 359:693-699.

29. Fiorentino, D.F., Zlotnik, A., Mosmann, T.R., Howard, M., and O'Garra, A. 1991. IL-10 inhibits cytokine production by activated macrophages. J. Immunol. 147:3815-3822.

30. Schottelius, A.J., Mayo, M.W., Sartor, R.B., and Baldwin, A.S.J. 1999. Interleukin-10 signaling blocks inhibitor of $\mathrm{\kappa B}$ kinase activity and nuclear factor $\kappa \mathrm{B}$ DNA binding. J. Biol. Chem. 274:31868-31874.

31. Kühn, R., Löhler, J., Rennick, D., Rajewsky, K., and Müller, W. 1993. Interleukin-10-deficient mice develop chronic enterocolitis. Cell. 75:263-274.

32. Herfarth, H.H., Mohanty, S.P., Rath, H.C., Tonkonogy, S., and Sartor, R.B. 1996. Interleukin 10 suppresses experimental chronic, granulomatous inflammation induced by bacterial cell wall polymers. Gut. 39:836-845.

33. Graham, M.F., Bryson, G.R., and Diegelmann, R.F. 1990. Transforming growth factor beta 1 selectively augments collagen synthesis by human intestinal smooth muscle cells. Gastroenterology. 99:447-453.

34. Babyatsky, M.W., Rossiter, G., and Podolsky, D.K. 1996. Expression of transforming growth factors $\alpha$ and $\beta$ in colonic mucosa in inflammatory bowel disease. Gastroenterology. 110:975-984.

35. Arsura, M., Wu, M., and Sonenshein, G.E. 1996 TGF $\beta 1$ inhibits NF- $\mathrm{KB} /$ Rel activity inducing apoptosis of B cells: transcriptional activation of
IкB $\alpha$. Immunity. 5:31-40.

36. Powell, P.P., Dixon, L.K., and Parkhouse, R.M.E. 1996. An IкB homolog encoded by African swine fever virus provides a novel mechanism for downregulation of proinflammatory cytokine responses in host macrophages. J. Virol. 70:8527-8533.

37. Soumelis, V., et al. 2002. Human epithelial cells trigger dendritic cell-mediated allergic inflammation by producing TSLP. Nat. Immunol. 3:673-680.

38. Bondeson, J., Browne, K.A., Brennan, F.M., Foxwell, B.M.J., and Feldmann, M. 1999. Selective regulation of cytokine induction by adenoviral gene transfer of I $\mathrm{B} \alpha$ into human macrophages: lipopolysaccharide-induced, but not zymosaninduced, proinflammatory cytokines are inhibited, but IL-10 is nuclear factor- $\mathrm{KB}$ independent. J. Immunol. 162:2939-2945.

39. Rugtveit, J., et al. 1997. Cytokine profiles differ in newly recruited and resident subsets of mucosal macrophages from inflammatory bowel disease. Gastroenterology. 112:1493-1505.

40. Wahl, L.M., and Smith, P.D. 1991. Isolation of macrophages/monocytes from human peripheral blood and tissues. In Current protocols in immunology. J.E. Coligan, A.M. Kruisbeek, D.H. Marguilies, E.M. Shevach, and W. Strober, editors. John Wiley \& Sons Inc. New York, New York, USA. 7.6.1-7.6.8.

41. Redman, T.K., Britt, W.J., Wilcox, C.M., Graham, M.F., and Smith, P.D. 2002. Human cytomegalovirus enhances chemokine production by lipopolysaccharide-stimulated lamina propria macrophages. J. Infect. Dis. 185:584-590.

42. Zhou, L.J., and Tedder, T.F. 1996. CD14+ blood monocytes can differentiate into functionally mature CD $83^{+}$dendritic cells. Proc. Natl. Acad. Sci. U. S. A. 93:2588-2592.

43. Meng, G., et al. 2002. Primary intestinal epithelial cells selectively transfer R5 HIV-1 to $\mathrm{CCR}^{+}$cells. Nat. Med. 8:150-156.

44. Monteyne, P., Guillaume, B., and Sindic, C.J.M. 1998. BB7-1 (CD80), B7-2 (CD86), interleukin-12 and transforming growth factor- $\beta$ mRNA expression in CSF and peripheral blood mononuclear cells from multiple sclerosis patients. J. Neuroimmunol. 91:198-203. 